\title{
BrainCheck: Validation of a Computerized Cognitive Test Battery for Detection of Mild Cognitive Impairment and Dementia
}

\author{
Siao $\mathrm{Ye}^{1}$, Bin Huang ${ }^{2,}$, Kevin Sun², Huy Q. Phi ${ }^{3}$, Brian Ko ${ }^{3}$, Carolyn M. Parsey ${ }^{3}$, Reza \\ Hosseini Ghomi ${ }^{2,3, *}$
}

${ }^{1}$ Department of Biosciences, Rice University, Houston, TX, 77005, USA

${ }^{2}$ BrainCheck, Inc, Houston, TX, 77021, USA

${ }^{3}$ Department of Neurology, University of Washington School of Medicine, Seattle, WA, 98195, USA

"Corresponding author: Bin Huang (bin@braincheck.com), BrainCheck, Inc, Houston, TX, 77021, USA. Reza Hosseini Ghomi (reza@braincheck.com), BrainCheck, Inc, Houston, TX, 77021, USA.

\begin{abstract}
Early detection of dementia is critical for intervention and care planning, but remains difficult. This study evaluated a computerized cognitive testing battery (BrainCheck) for its diagnostic accuracy and ability to distinguish the severity of cognitive impairment. 99 participants diagnosed with Dementia, Mild Cognitive Impairment $(\mathrm{MCl})$, or Normal Cognition (NC) completed the BrainCheck battery. Statistical analyses compared participant's performance on BrainCheck based on their diagnosis group BrainCheck battery performance showed significant differences between the $\mathrm{NC}, \mathrm{MCl}$, and Dementia groups, achieving $\geq 88 \%$ sensitivity/specificity for separating NC from Dementia, and $\geq 77 \%$ sensitivity/specificity in separating the $\mathrm{MCl}$ group from $\mathrm{NC} /$ Dementia groups. Three-group-classification found true positive rates $\geq 80 \%$ for the $\mathrm{NC}$ and Dementia groups and $\geq 60 \%$ for the $\mathrm{MCl}$ group. BrainCheck was able to distinguish between diagnoses of Dementia, $\mathrm{MCl}$, and $\mathrm{NC}$, providing a potentially reliable tool for early detection of cognitive impairment.
\end{abstract}




\section{INTRODUCTION}

In proportion with the increasingly aging population, the incidence of dementia is on the rise; projected to affect nearly 14 million people in the United States and upwards of 152 million people globally in the coming decades [1-3]. Current rates of undetected dementia are reported as high as $61.7 \%$ [4], and available treatments are limited to promoting quality of life rather than reversal or cure of the disease process. The ability to properly identify and treat dementia at this scope requires an active approach focused on early identification and intervention. Early detection of dementia provides access to timely interventions and knowledge to promote patient health and quality of life before symptoms become severe. Known treatment interventions help to address underlying conditions and minimize distressing symptoms, providing reason to implement these earlier on. Early and accurate diagnosis allows for proper preparation of patients, caregivers, and families which results in improved caregiver well-being and delayed institutionalization [5, 6]. Further, it helps to characterize early-stage dementia patients for clinical trials, exploring the latest therapeutics and validating biomarkers indicative of specific pathologies. Despite the benefits, early detection is a current challenge with current clinical protocols, leaving many patients undiagnosed until symptoms are more apparent in later stages of the illness.

Considered an early symptomatic clinical stage of dementia, mild cognitive impairment (MCl) signifies a level of cognitive impairment between normal cognition (NC) and dementia [7]. While not all $\mathrm{MCl}$ cases progress, the conversion rate of $\mathrm{MCl}$ to dementia has been observed to be approximately $5-10 \%$ [8]. This stresses the importance of $\mathrm{MCl}$ identification in the early detection and clinical intervention for dementia, included in recommendations from The National Institute on Aging and the Alzheimer's Association [9]. Detection of $\mathrm{MCl}$ has been fairly successful using brief cognitive screening assessments. The widely used Montreal Cognitive Assessment (MoCA) has demonstrated $83 \%$ sensitivity and $88 \%$ specificity in distinguishing $\mathrm{MCl}$ from $\mathrm{NC}$ its ability to distinguish dementia from $\mathrm{MCl}$ has demonstrated $90 \%$ sensitivity and $63 \%$ specificity [10, 11]. The Saint Louis University Mental Status (SLUMS) exam and the Mini-Mental State Examination (MMSE) also show the ability to distinguish impaired 
individuals. For example, the diagnostic accuracy of the MMSE has been reported to be $62 \%$ sensitivity and $87 \%$ specificity for distinguishing $\mathrm{MCl}$ from $\mathrm{NC}$ and $80 \%$ sensitivity and $85 \%$ specificity for distinguishing dementia from $\mathrm{MCI}[12,13]$. Similar performance has been observed with the SLUMS exam, reporting $94 \%$ sensitivity and $87 \%$ specificity for diagnosing dementia and $82 \%$ sensitivity and $86 \%$ specificity for diagnosing cognitive impairment [14]. While traditional 'paper and pen' based versions of these assessments have typically been used in standard practice, digitized or computerized versions are now available; however, they have been slow in adoption in clinical practice. Although these screening tests do well in their ability to detect $\mathrm{MCl}$, they often are utilized to prompt an indication for further comprehensive testing to better specify patterns of cognitive impairment seen in neurological disorders [15].

After a diagnosis of $\mathrm{MCl}$, there is often a referral for neuropsychological testing (NPT); a comprehensive evaluation of cognitive domains (e.g., attention, working memory, language, visuospatial skills, executive functioning, memory), that are used to support clinical diagnoses and further delineate specific neurocognitive disorders. NPT can determine patterns of cognitive functioning that relate to normal aging, $\mathrm{MCl}$, and dementia progression with specificities from $67-99 \%$ [16]. A major strength of NPT is the ability to characterize cognitive impairments, providing clues to underlying pathology, and thereby improving diagnostic accuracy to guide appropriate treatment. However, NPT comes with downsides including financial cost, long appointment times, and high levels of required training and expertise to conduct and interpret tests. To address these pitfalls and meet future demands, computerized and/or digitized NPT have also been developed to address issues of accessibility and efficiency [17, 18]. Prior studies have shown that some computerized cognitive tests demonstrate high accuracy in differentiating dementia patients from healthy participants, but do not have adequate psychometrics to distinguish $\mathrm{MCl}$ from dementia [19-22]. Ideally, computerized cognitive tests would aim to be more rapid and maximize accessibility to both patients and providers to address the expected uptick in dementia. This would also yield multiple benefits including maintaining testing standardization, alleviating time pressures of modern clinical practice, and providing a comprehensive assessment of 
medRxiv preprint doi: https://doi.org/10.1101/2020.11.10.20229369; this version posted November 13, 2020. The copyright holder for this preprint (which was not certified by peer review) is the author/funder, who has granted medRxiv a license to display the preprint in perpetuity.

It is made available under a CC-BY-NC 4.0 International license .

cognitive function to strengthen a clinical diagnosis. Importantly, in the new era of practicing amidst the COVID-19 pandemic [23], increasing the accessibility of remote cognitive testing for vulnerable/high-risk patients is essential.

This study evaluated BrainCheck, a computerized cognitive test battery previously validated for its diagnostic accuracy for the detection of concussion [24] and dementia-related cognitive decline [25]. BrainCheck is portable, allows for self and remote administration, and can be reimbursed by insurance plans in the US. Furthering its validation for dementia-related cognitive decline, we sought to assess BrainCheck's utility as a diagnostic aid to accurately distinguish the severity of cognitive impairment using existing clinical diagnoses of Normal Cognition (NC), Mild Cognitive Impairment $(\mathrm{MCl})$, and Dementia. We compared BrainCheck scores to comprehensive clinical diagnosis (subjective cognitive impairment or $\mathrm{NC}, \mathrm{MCl}$, or Dementia). Our goal was to further demonstrate the utility of BrainCheck for cognitive assessment, specifically as a diagnostic aid in cases where NPT may be unavailable, or when a comprehensive evaluation is not indicated.

\section{METHODS}

\subsection{Recruitment}

This study was approved by the Institutional Review Board of The University of Washington for human subject participation. Participants were recruited using the University of Washington Alzheimer's Disease Research Center's (UW ADRC) research registry [26], a database of individuals willing to participate in dementia-related research. Those on the registry were contacted by phone or email provided within the registry. While there were no formal exclusionary criteria, those with listed addresses outside a 70 -mile radius of Seattle, Washington were not contacted to participate. If the person was unable to physically use an iPad, too cognitively impaired to understand or follow instructions, or if the primary contact (e.g., spouse) indicated that the person was unable to participate, they were not recruited for the study. When study procedures were modified from in-person to remote administration due to the COVID-19 pandemic (approximately March 2020), participants outside of the initial geographical range were 
contacted. We required that these participants had access to either an iPad with iOS 10 or later, or a touchscreen computer with Wi-Fi connectivity. A small number of participants were recruited via snowball sampling by participants who had completed the study.

Most participants from the research registry were former or current patients of a memory disorders clinic in Seattle, Washington where a recent clinical diagnosis by a physician had been made. Using their primary cognitive diagnosis by the memory clinic, participants were divided into one of three groups: 1) Normal Cognition (NC), indicated by subjective cognitive complaint or no diagnosis of cognitive impairment, 2) Mild Cognitive Impairment $(\mathrm{MCl})$, representing both amnestic $(\mathrm{aMCl})$ and non-amnestic (naMCl) subtypes, or 3) Dementia, which included dementia due to Alzheimer's Disease $(A D)$, Frontotemporal dementia, Vascular dementia, Lewy body dementia, Mixed dementia, or Atypical AD, delineated by the clinical diagnosis. Participants who did not have a formal diagnosis and denied cognitive symptoms or a history of cognitive impairment were placed into the NC group.

\subsection{Participant Characteristics and Demographics}

241 individuals were contacted to participate and 99 participants completed the study. Participant ages ranged from 47 to 90 years old (mean age $=70.7 ; S D=8.9$ ) and the sex distribution was balanced. The diagnosis groups consisted of 35 in the NC group, 22 in the $\mathrm{MCl}$ group, and 42 in the Dementia group. 75 participants completed BrainCheck via on-site administration and 24 participants completed BrainCheck via remote administration.

\subsection{Study Design and Procedures}

\subsubsection{On-site Administration}

Data collection for on-site administration was collected from October 2019 to February 2020. A session was held either in the participant's home or in a public setting that was well-lit, quiet, and distraction-free. Consent forms were reviewed and signed by the participant, or legally authorized representative, and examiner, with both parties 
medRxiv preprint doi: https://doi.org/10.1101/2020.11.10.20229369; this version posted November 13, 2020. The copyright holder for this preprint (which was not certified by peer review) is the author/funder, who has granted medRxiv a license to display the preprint in perpetuity.

It is made available under a CC-BY-NC 4.0 International license .

obtaining a copy. The study was designed for participants to complete one session with a moderator using a provided iPad (Model MR7G3LL/A) connected to Wi-Fi to complete the BrainCheck battery. Prior to testing, participants were briefed on BrainCheck, and moderator guidance was limited to questions and assistance requested by the participant during the practice portions. Participants received a gift card for participation at the conclusion of the study session.

\subsubsection{Remote Administration}

Due to the COVID-19 pandemic, study procedures were modified to accommodate stay-at-home orders in Washington state. Data collection resumed from April 2020 to May 2020, with modified procedures using remote administration. These participants provided written and verbal consent and were administered the BrainCheck battery remotely over a video call with the moderator. Participants used their personal iPads or touchscreen computer browser to complete the BrainCheck battery. The same method for on-site administration (described above) was used for remote administration.

\subsection{Measurements}

A short description of each of the 5 assessments that make-up the BrainCheck battery (V4.0.0) is listed in Table 1. More detailed descriptions may be found in a previous validation study [24]. After completion of the BrainCheck battery, the score of each assessment is calculated using assessment specific measurements by the BrainCheck software (shown in Table 1). The BrainCheck Overall Score is a single, cumulative score for the BrainCheck battery that represents general cognitive functioning. This score is calculated by taking the weighted average of all assessment scores. The normalized assessment scores and overall scores are corrected for participant age and device used (iPad versus computer) using the mean and standard deviation of the corresponding score from a normative database previously collected by BrainCheck. The score generated follows a standard normal distribution, where a lower score indicates lower assessment performance and cognitive functioning. 
medRxiv preprint doi: https://doi.org/10.1101/2020.11.10.20229369; this version posted November 13, 2020. The copyright holder for this preprint (which was not certified by peer review) is the author/funder, who has granted medRxiv a license to display the preprint in perpetuity.

It is made available under a CC-BY-NC 4.0 International license .

TABLE 1. Cognitive Assessments in BrainCheck

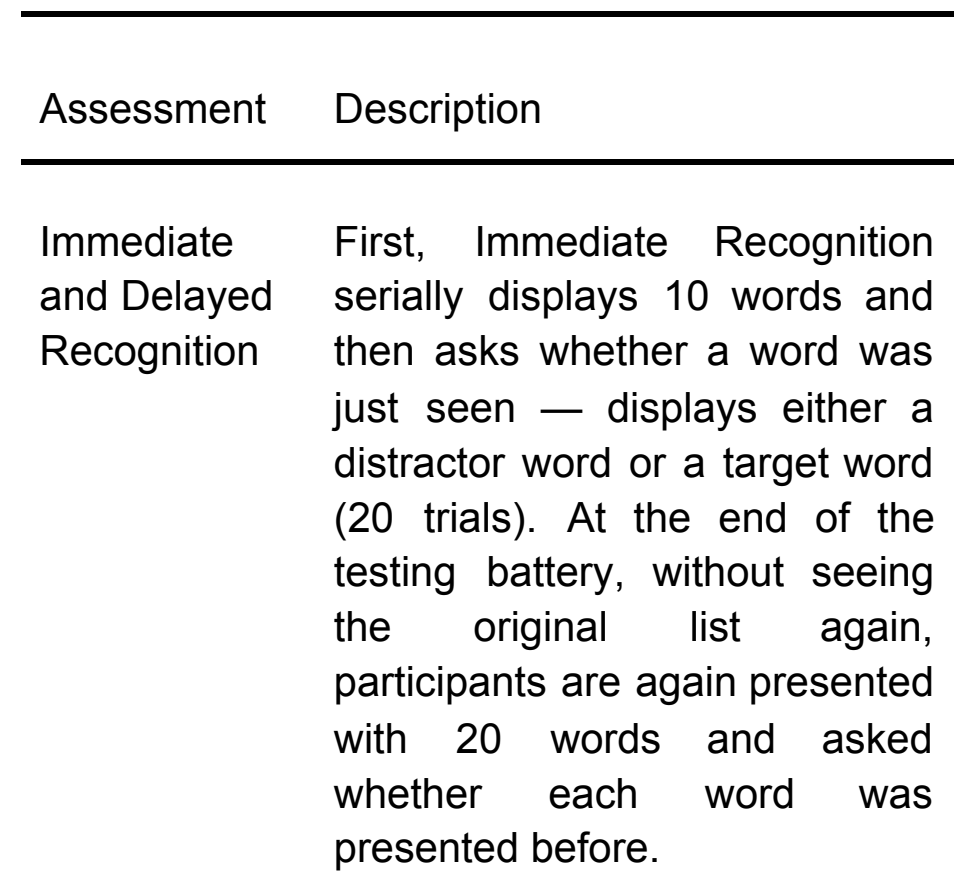

Digit Symbol Participants must match an

Median duration time

Executive

Substitution

arbitrary correspondence of

of matching the

function

symbols to digits; when

digits and symbols

presented with a new symbol, they input the corresponding digit as quickly as possible.

Flanker

Participants are presented with a target item (in this case, a central arrow) flanked by Median reaction time Alertness, of correct direction spatial congruent $(>>>>>)$, or choice awareness, incongruent $(\ll<<<)$ arrows. and Participants identify the direction executive of the target as quickly and accurately as possible.

Stroop Participants are instructed to find a word matching the given Median reaction time Executive name of a color. There are three of incongruent function types of trials: NEUTRAL in and which all words are presented impulsivity with black font, CONGRUENT in word-color pairs function 
which the word and font color are the same (e.g., the word RED presented in red font), and NON-CONGRUENT in which the word indicates a different color than the font (e.g., the word RED presented in green font). A time-out mechanism is triggered if there is not a completion of a trial in the assessment within 30 seconds.
Trail Making

Test

\begin{abstract}
Participants are instructed to connect a set of 25 dots in their correct order as rapidly as possible. Trail Making Test A uses only numbers (1 through 25), while Trail Making Test $B$ employs alternating numbers and letters $(1-A-2-B-3-$ $C$ - ...). A time-out mechanism is triggered if there is not a completion of a trial in the assessment within 30 seconds
\end{abstract}

\subsection{Statistical Analysis}

To evaluate BrainCheck performance among participants in different diagnosis groups, Kruskal-Wallis tests with post-hoc Dunn's tests were conducted on individual BrainCheck assessment scores and BrainCheck Overall Scores. P-values were corrected using the Benjamini-Hochberg method for multiple comparisons. To assess the accuracy of the BrainCheck Overall Score in binary classification of participants in the different diagnosis groups ( $\mathrm{NC}$ vs. Dementia, $\mathrm{NC}$ vs. $\mathrm{MCl}$ and $\mathrm{MCl}$ vs. Dementia), receiver operating characteristic (ROC) curves with area under the curve (AUC) calculations were generated to determine diagnostic sensitivity and specificity. In assessing BrainCheck for three group classification, we used an $\mathrm{R}$ package developed by Luo et al. [27], to define optimal cutoffs for the BrainCheck Overall Score and find the 
medRxiv preprint doi: https://doi.org/10.1101/2020.11.10.20229369; this version posted November 13, 2020. The copyright holder for this preprint (which was not certified by peer review) is the author/funder, who has granted medRxiv a license to display the preprint in perpetuity.

It is made available under a CC-BY-NC 4.0 International license .

maximum diagnostic accuracy. The analysis was performed using Python version 3.8.5 and $R$ version 3.6 .2 programming languages.

\section{RESULTS}

\subsection{Completion of Assessments}

We found most participants in the NC group were able to complete the assessments whereas the Dementia group had a higher 'timeout' rate, with $\mathrm{MCl}$ falling in between the two (Figure 1). The timeout function occurs when a participant can not complete a trial of the assessment in 30 seconds; it is embedded in the Stroop and Trails $A / B$ assessments. Timeouts were mainly due to response delays; where participants were attempting the test but could not answer quickly enough. Overall, the Dementia group took significantly more time to complete the BrainCheck battery $(m=35.4 \mathrm{~min}, s d=21.4$ $\min$ ) compared to the NC group ( $m=18.2 \mathrm{mins}, s d=3.7 \mathrm{mins}$ ), on average.
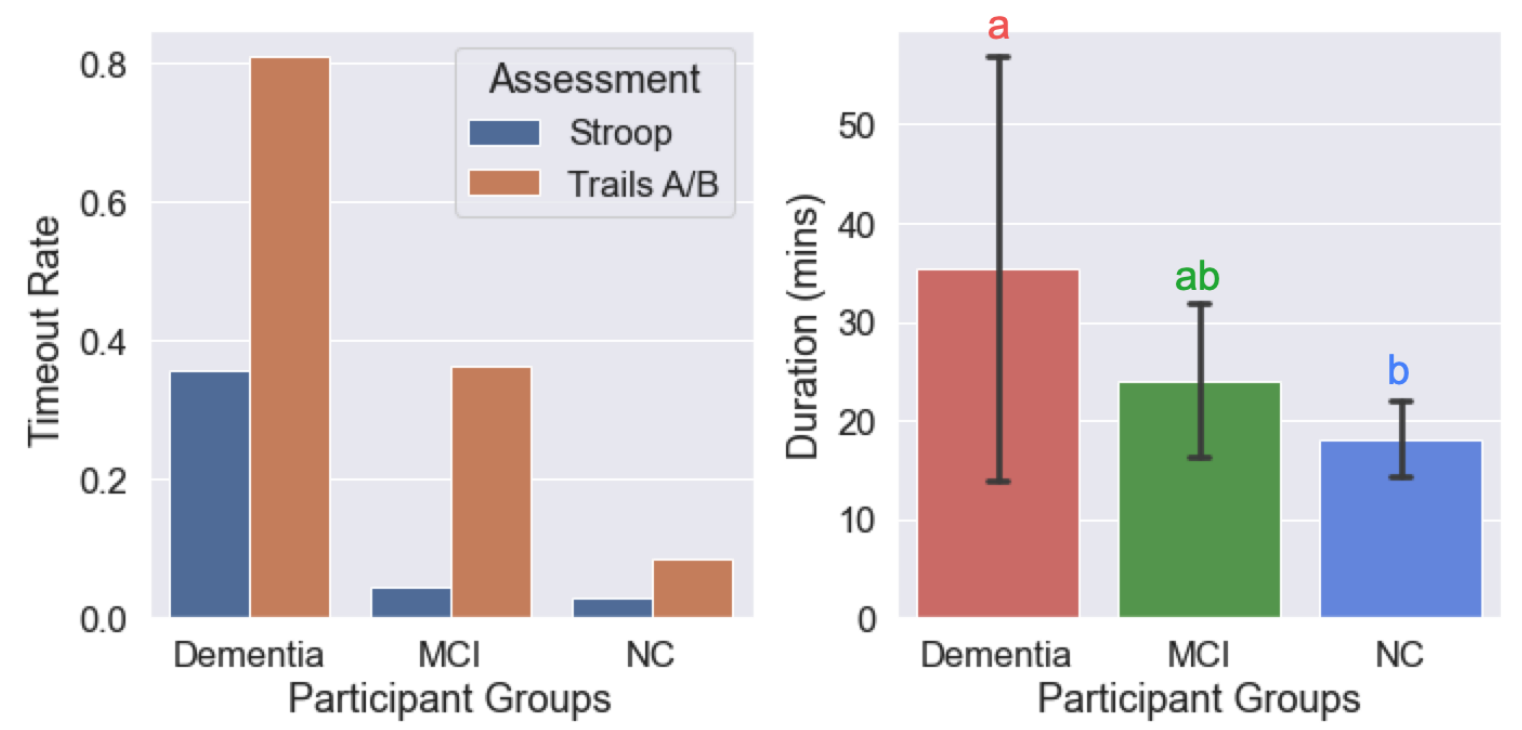

FIGURE 1: Completion of Assessments and Durations to Complete BrainCheck Battery (LEFT) Timeout rates of the Stroop and Trails A/B assessments for each diagnosis group. The BrainCheck Stroop and Trails $A / B$ assessments timeout if participants cannot complete a trial of the assessment in 30 seconds.

(RIGHT) Duration (mins) to complete the BrainCheck Battery for each diagnosis group. Letters $(a, b)$ indicate significant differences $(p<0.05)$ on the post-hoc Dunn's test. Any two groups sharing a letter are not significantly different. 
medRxiv preprint doi: https://doi.org/10.1101/2020.11.10.20229369; this version posted November 13, 2020. The copyright holder for this preprint (which was not certified by peer review) is the author/funder, who has granted medRxiv a license to display the preprint in perpetuity.

It is made available under a CC-BY-NC 4.0 International license .

\subsection{BrainCheck Performance}

BrainCheck assessments were compared across the three groups. Individual scores, such as the BrainCheck Overall Score, were normalized for age and device. Overall, participants with greater cognitive impairment showed lower BrainCheck assessment scores. All individual assessments showed significant differences in performance between the NC and Dementia groups. Three of the seven assessments (Digit Symbol, Flanker, and Trails A) showed significant differences in performance between all three groups on post-hoc Dunn's test (Table 2). The Immediate and Delayed Recognition tests showed significant differences $(p<0.05)$ in performance between the $\mathrm{MCl}$ and $\mathrm{NC}$ group, but there was not a significant difference between the $\mathrm{MCl}$ and Dementia group (Table 2). The Stroop and Trails B tests showed significant differences between the NC and Dementia groups but could not significantly differentiate the $\mathrm{MCl}$ group from the other groups (Table 2). 
medRxiv preprint doi: https://doi.org/10.1101/2020.11.10.20229369; this version posted November 13, 2020. The copyright holder for this preprint (which was not certified by peer review) is the author/funder, who has granted medRxiv a license to display the preprint in perpetuity.

It is made available under a CC-BY-NC 4.0 International license .

TABLE 2. Results of Kruskal-Wallis $H$ test and post-hoc Dunn's test for individual BrainCheck Assessment performance and Battery performance across the diagnosis groups

\begin{tabular}{|c|c|c|c|c|c|c|c|c|}
\hline \multirow{2}{*}{ Assessments } & \multicolumn{3}{|c|}{$\begin{array}{c}\text { Diagnosis Group Assessment } \\
\text { Mean Score (SD) }\end{array}$} & \multirow{2}{*}{$X^{2}$} & \multirow{2}{*}{$\begin{array}{c}\text { Kruskal } \\
\text { Wallis } \\
p\end{array}$} & \multicolumn{3}{|c|}{$\begin{array}{c}\text { Post-hoc Dunn's Test Pairwise } \\
\text { Comparison } p\end{array}$} \\
\hline & $\mathrm{NC}$ & $\mathrm{MCl}$ & Dementia & & & $\begin{array}{l}\text { NC vs. } \\
\text { Dementia }\end{array}$ & $\begin{array}{l}\mathrm{NC} \text { vs. } \\
\mathrm{MCl}\end{array}$ & $\begin{array}{l}\mathrm{MCl} \text { vs. } \\
\text { Dementia }\end{array}$ \\
\hline $\begin{array}{l}\text { Immediate } \\
\text { Recognition }\end{array}$ & $\begin{array}{c}0.03 \\
(1.79)\end{array}$ & $\begin{array}{l}-2.03 \\
(2.07)\end{array}$ & $\begin{array}{l}-3.49 \\
(2.58)\end{array}$ & 38.65 & $<0.001$ & $<0.001$ & $<0.01$ & 0.08 \\
\hline $\begin{array}{l}\text { Delayed } \\
\text { Recognition }\end{array}$ & $\begin{array}{c}0.17 \\
(1.14)\end{array}$ & $\begin{array}{l}-2.08 \\
(2.32)\end{array}$ & $\begin{array}{l}-2.86 \\
(1.75)\end{array}$ & 42.17 & $<0.001$ & $<0.001$ & $<0.01$ & 0.13 \\
\hline $\begin{array}{l}\text { Digit Symbol } \\
\text { Substitution* }\end{array}$ & $\begin{array}{l}-0.57 \\
(6.56)\end{array}$ & $\begin{array}{l}-0.82 \\
(2.77)\end{array}$ & $\begin{array}{l}-13.67 \\
(22.97)\end{array}$ & 33.32 & $<0.001$ & $<0.001$ & 0.01 & 0.02 \\
\hline Flanker* & $\begin{array}{c}0.19 \\
(1.21)\end{array}$ & $\begin{array}{l}-1.95 \\
(4.89)\end{array}$ & $\begin{array}{c}-8.45 \\
(13.38)\end{array}$ & 33.62 & $<0.001$ & $<0.001$ & 0.04 & $<0.01$ \\
\hline Stroop & $\begin{array}{l}-0.49 \\
(0.47)\end{array}$ & $\begin{array}{l}-0.83 \\
(0.93)\end{array}$ & $\begin{array}{l}-1.67 \\
(1.83)\end{array}$ & 12.39 & $<0.01$ & $<0.01$ & 0.25 & 0.07 \\
\hline Trails $A^{*}$ & $\begin{array}{c}0.22 \\
(0.89)\end{array}$ & $\begin{array}{l}-0.73 \\
(1.57)\end{array}$ & $\begin{array}{l}-5.40 \\
(10.07)\end{array}$ & 28.65 & $<0.001$ & $<0.001$ & 0.03 & 0.02 \\
\hline Trails B & $\begin{array}{l}-0.35 \\
(4.33)\end{array}$ & $\begin{array}{l}-0.85 \\
(4.25)\end{array}$ & $\begin{array}{l}-3.70 \\
(6.89)\end{array}$ & 8.36 & 0.01 & 0.01 & 0.49 & 0.10 \\
\hline $\begin{array}{l}\text { Normalized } \\
\text { BrainCheck } \\
\text { Overall Score }\end{array}$ & $\begin{array}{c}0.38 \\
(2.01)\end{array}$ & $\begin{array}{l}-2.27 \\
(2.91)\end{array}$ & $\begin{array}{l}-5.81 \\
(3.25)\end{array}$ & 55.03 & $<0.001$ & $<0.001$ & $<0.001$ & $<0.01$ \\
\hline
\end{tabular}

Significant $p$-values are shown in bold. Assessments marked with * indicate significant differences across all three diagnosis groups. p-values are adjusted with the Benjamini-Hochberg method.

The BrainCheck Overall Score is a composite of all individual assessments within the BrainCheck battery, representing overall performance (See details in Method 2.4). Using an existing normative population database, partly compiled from controls in previous studies [24,25], the Overall Score was adjusted for age and the device used to generate the normalized BrainCheck Overall Scores. The normalized BrainCheck Overall Scores differed significantly among these three groups $(p<0.05)$. The NC group 
scored significantly higher than the $\mathrm{MCl}$ and Dementia groups. The Dementia group demonstrated significantly lower scores than the other two groups (Figure 2).

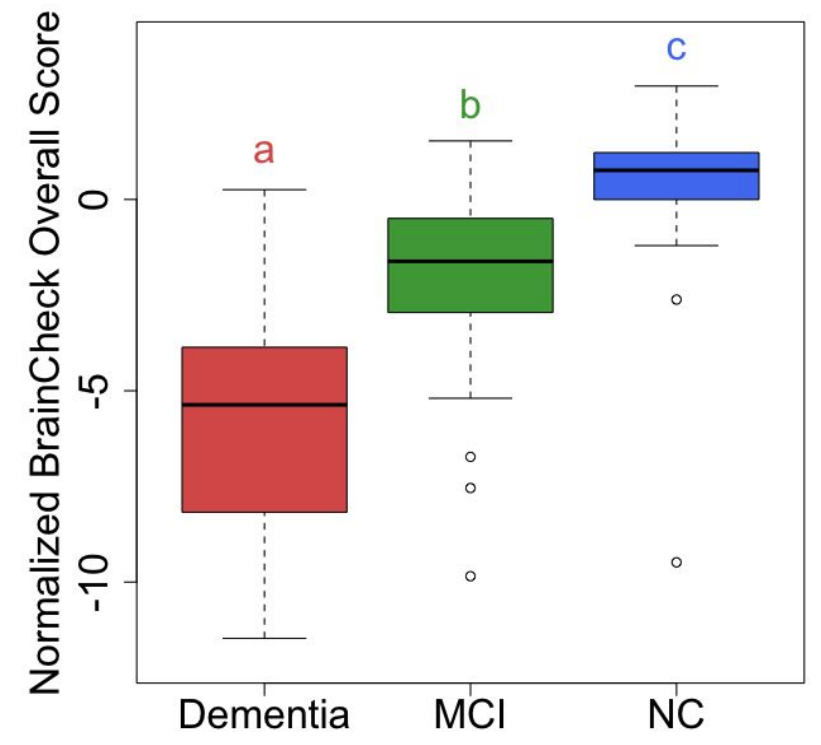

FIGURE 2: Comparison of Normalized BrainCheck Overall Scores Among Groups.

The Normalized BrainCheck Overall Score follows a standard normal distribution. Letters $(a, b, c)$ indicate significant differences $(p<0.05)$ on the post-hoc Dunn's test.

\subsection{BrainCheck Diagnostic Accuracy}

Using ROC analysis, Braincheck Overall Scores achieved a sensitivity of $94 \%$ and a specificity of $88 \%$ for classifying NC and Dementia participants (AUC=0.954); a sensitivity of $83 \%$ and a specificity of $86 \%$ for classifying between $\mathrm{NC}$ and $\mathrm{MCl}$ participants ( $A \cup C=0.842$ ); and a sensitivity of $77 \%$ and a specificity of $83 \%$ for classifying between $\mathrm{MCl}$ and Dementia participants (AUC=0.785) (Figure 3). 
medRxiv preprint doi: https://doi.org/10.1101/2020.11.10.20229369; this version posted November 13, 2020. The copyright holder for this preprint (which was not certified by peer review) is the author/funder, who has granted medRxiv a license to display the preprint in perpetuity.

It is made available under a CC-BY-NC 4.0 International license .
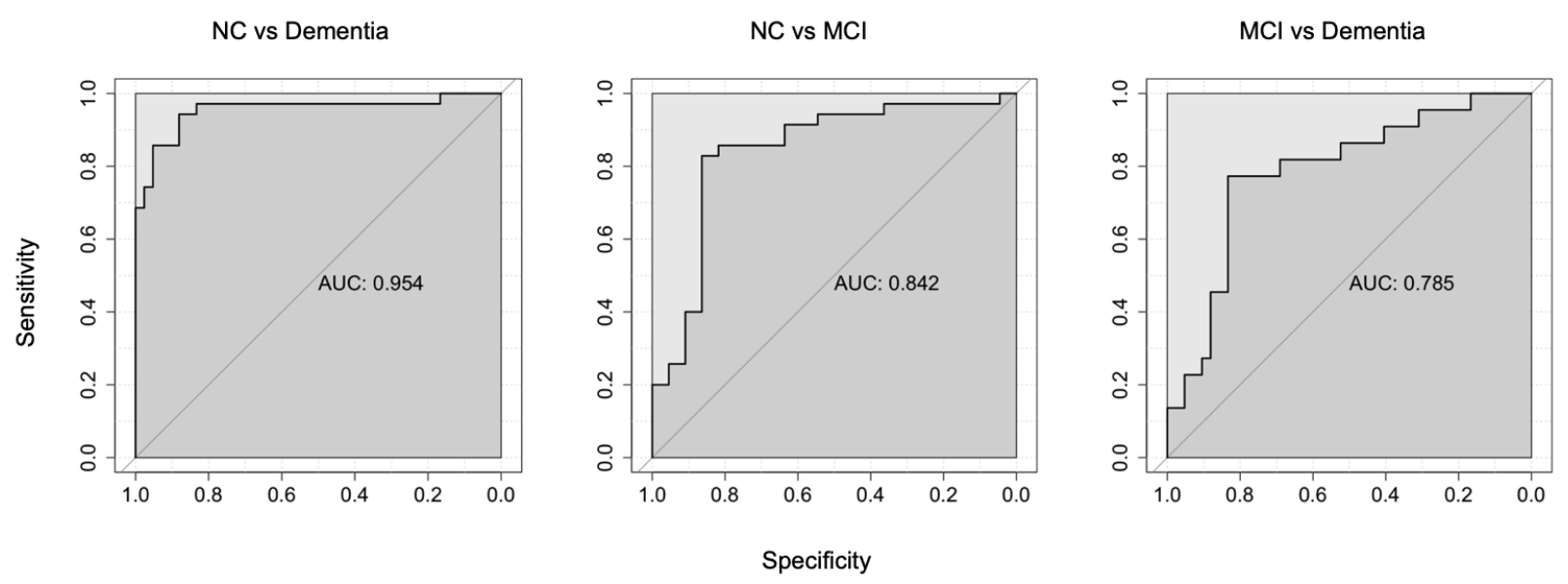

FIGURE 3. ROC Curves for the BrainCheck Overall Score in Classifying Participants of Different Groups

ROC curves with AUC's for the BrainCheck Overall Score in binary classification of:

(LEFT) NC vs. Dementia

(MIDDLE) NC vs. MCl

(RIGHT) MCl vs. Dementia.

Using methods described by Luo and colleagues for three group classification [27], the optimal lower and upper cutoffs of the normalized BrainCheck Overall Score in maximizing diagnostic accuracy were -3.64 and -0.06 , respectively. This achieved true positive rates of $83 \%$ for the NC group, $64 \%$ for the $\mathrm{MCl}$ group, and $83 \%$ for the Dementia group (Figure 4). 

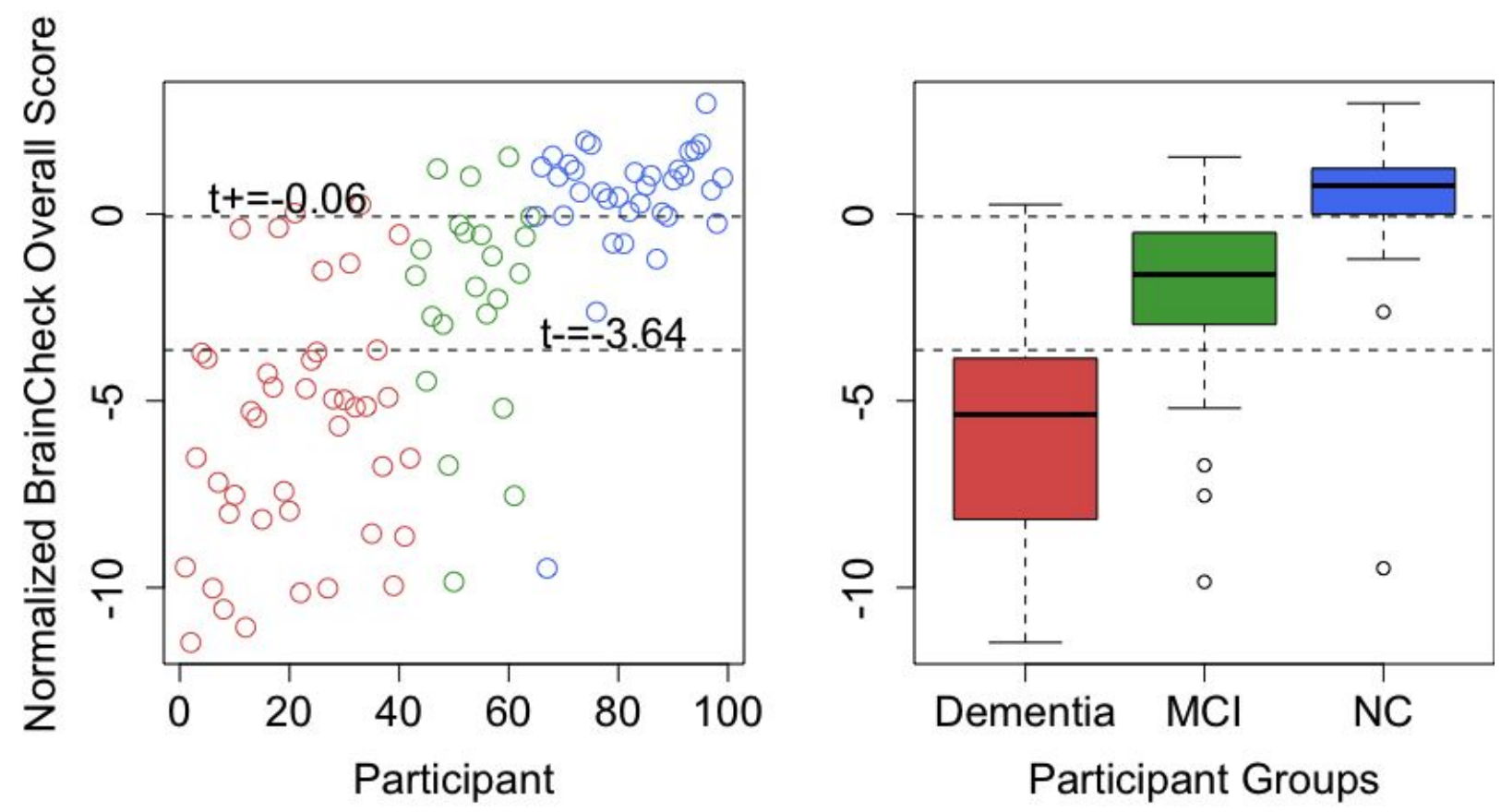

FIGURE 4: Optimal BrainCheck Cutoff Scores for Distinguishing $\mathrm{NC}, \mathrm{MCl}$, and Dementia Groups

(LEFT) Individual participant normalized BrainCheck Overall Scores, where the $x$-axis is the index of the participant, sorted by primary diagnosis (Dementia - red, $\mathrm{MCl}$ - green, and $\mathrm{NC}$ - blue).

(RIGHT) Boxplots of normalized BrainCheck Overall Scores for each diagnosis group. The Normalized BrainCheck Overall Score follows a standard normal distribution. The dashed lines label the optimal cutoff scores for distinguishing the diagnosis groups.

\section{DISCUSSION}

Consistent with prior findings in concussion [24] and dementia/cognitive decline [25] samples, this study demonstrated that BrainCheck is consistent in its capability to detect cognitive impairment. Our study demonstrated that BrainCheck can detect $\mathrm{MCl}$, and reliably differentiate between the severity of cognitive impairments in the diagnosis groups ( $\mathrm{NC}, \mathrm{MCl}$, and Dementia). As expected, participants with more severe cognitive impairment performed worse across the individual assessments and on BrainCheck Overall Scores. The BrainCheck Overall Scores separated participants of different diagnostic groups successfully with high sensitivity and specificity. 
BrainCheck Overall Scores were more robust in distinguishing these groups where participants in the Dementia group had significantly lower scores than ones in the NC group. The BrainCheck battery was able to distinguish between NC and Dementia participants, with $94 \%$ sensitivity and $88 \%$ specificity. These findings show that the BrainCheck Overall Score demonstrates better accuracy for differentiating NC from Dementia, compared to the MMSE, SLUMS and MoCA screening measures[14, 15, 29]. People with $\mathrm{MCl}$ usually experience fewer cognitive deficits and preserved functioning in activities of daily living compared to those with Dementia [30], and our findings of sensitivity and specificity with separating $\mathrm{MCl}$ from other groups were slightly lower than the NC versus Dementia differentiations (Figure 3). Nonetheless, the BrainCheck Overall Score showed sensitivities and specificities $>80 \%$ in distinguishing $\mathrm{MCl}$ from NC and Dementia groups, which is comparable to the MoCA, SLUMS, and MMSE [11-15]. Furthermore, a review of validated computerized cognitive tests indicated AUC's ranging from $0.803-0.970$ for detecting $\mathrm{MCl}$, and AUC's of 0.98 and 0.99 in detecting dementia due to $A D$ [28], which were comparable with the results found in this study.

Although not all individual assessments in the BrainCheck battery could differentiate $\mathrm{NC}, \mathrm{MCl}$, and Dementia, we observed a general trend for each assessment showing that Dementia participants had the lowest scores whereas the NC participants had the highest scores. The individual assessments that did show significant differences in the scores between $\mathrm{NC}$ and $\mathrm{MCl}$ groups and between Dementia and $\mathrm{MCl}$ groups included the Digit Symbol, Flanker, and Trails A. Notably, in this study the BrainCheck Digit Symbol test showed significant differences in performance between all three diagnosis groups, whereas a previous study found that the BrainCheck Digit Symbol test did not show significant differences between cognitively healthy and cognitively impaired groups $(n=18, p=0.29)$ [25]. This is likely due to the present study having a larger sample size. The individual assessments with no significant differences between the $\mathrm{MCl}$ group and the $\mathrm{NC} /$ Dementia groups were the BrainCheck Stroop and Trails B tests (Table 2). Both of these tests include timeout mechanisms if participants are unable to complete the test, and time out rates were higher in the more cognitively impaired groups (Figure 1). 
In comparison to comprehensive NPT, which can typically last a few hours and sometimes require multiple visits [30], BrainCheck demonstrated shorter test duration, with average completion times of 18.2 mins ( $s d=3.7$ mins) for NC participants and 35.4 $\min (s d=21.4 \mathrm{~min}$ ) for dementia participants (Figure 1). Shorter test durations observed in individuals with no/less cognitive impairment suggest that computerized cognitive tests could be useful for rapid early detection in this population, prompting further evaluation, whereas those with dementia have likely already undergone a comprehensive evaluation. The wide variance in completion time for the Dementia group may have uncovered the difficulty participants with more severe cognitive impairment may have faced in completing the BrainCheck battery, in comparison to the lower variance observed in the NC group.

A limitation of this study was that all participants were not professionally evaluated and diagnosed by a physician at the time of BrainCheck testing. Thus, participants were placed into the diagnosis groups based on their most recent clinical diagnosis available in their electronic health record, or for the few NC participants without medical evaluations, based on their report of no cognitive symptoms or diagnosis or cognitive impairment. The time period from the most recent clinical diagnosis to the date of BrainCheck testing varied among the diagnosis groups; where the Dementia group had the fewest days from last clinical evaluation ( $m=111$ days; $s d=104)$, followed by the $\mathrm{MCl}$ group ( $m=342$ days, $s d=345$ ) and the NC group ( $m=753$ days; $s d=570)$. These large time intervals in a degenerative population leave room for cognition to worsen over time, potentially blurring the lines in severity of cognitive impairment, where participants may have progressed to $\mathrm{MCl}$ from $\mathrm{NC}$, and to Dementia from $\mathrm{MCl}$ during that time period. This would make the distinguishing of NC from cognitive impairment more difficult, yet diagnostic accuracy among the groups still remains high. Furthermore, the mean number of days since the last clinical evaluation for NC participants was as high as 753 days. This could suggest that the NC participants did not feel an inclination to seek out further cognitive evaluation during the extended time period, and not have experienced noticeable cognitive decline. Future validity studies should ensure that a physician 
medRxiv preprint doi: https://doi.org/10.1101/2020.11.10.20229369; this version posted November 13, 2020. The copyright holder for this preprint (which was not certified by peer review) is the author/funder, who has granted medRxiv a license to display the preprint in perpetuity.

It is made available under a CC-BY-NC 4.0 International license .

evaluation and diagnosis occur closer to the time of BrainCheck testing to address these limitations.

When administration type was considered, scores showed significant differences among all three groups for onsite administration but not for remote administration. While scores showed similar trends, the sample size of $\mathrm{NC}(n=6)$ and $\mathrm{MCl}(\mathrm{n}=6)$ within the remote groups were fairly small. While remote administration was not designed within the original study, stay at home orders due to COVID-19 required modifications, and efforts were made to provide preliminary data for remote use and self-administration abilities. With preliminary outcomes indicating feasibility for remote administration, a more robust study and increased sample size will be needed to fully validate BrainCheck's cognitive assessment via it's remote and self-administered feature.

\section{Future Directions}

The use of computerized cognitive tests is an opportunity to increase test accessibility for an aging population and an increasing presence of cognitive impairment. Remote test options with quick and accurate results could save on time and costs. Technological advances have allowed for these tools to obtain greater sensitivity and specificity as well [28]. Our findings in this study demonstrate that BrainCheck can distinguish between three different levels of cognitive impairment, $\mathrm{NC}, \mathrm{MCl}$, and Dementia. This study paves the way for a comprehensive longitudinal study, exploring BrainCheck in early detection of dementia and monitoring of cognitive symptoms over time, including comparison to 'gold standard' neuropsychological assessments. BrainCheck is automated, self-administrable, and quick to administer. These qualities are critical to increasing accessibility, especially in early detection, for a population facing an expected increase of dementia in upcoming years. Increasing access may lead to the growth in the normative data needed to better characterize dementia subtypes and provide earlier detection and diagnostic utility. 


\section{REFERENCES}

[1] 2020 Alzheimer's disease facts and figures - 2020 - Alzheimer's \&amp; Dementia Wiley Online Library n.d. https://alz-journals.onlinelibrary.wiley.com/doi/10.1002/alz.12068 (accessed May 22, 2020).

[2] Matthews KA, Xu W, Gaglioti AH, Holt JB, Croft JB, Mack D, et al. Racial and ethnic estimates of Alzheimer's disease and related dementias in the United States (2015-2060) in adults aged $\geq 65$ years. Alzheimers Dement J Alzheimers Assoc 2019;15:17-24. https://doi.org/10.1016/j.jalz.2018.06.3063.

[3] O'Connor D. World Alzheimer Report 2019: Attitudes to dementia n.d.:160.

[4] Lang L, Clifford A, Wei L, Zhang D, Leung D, Augustine G, et al. Prevalence and determinants of undetected dementia in the community: a systematic literature review and a meta-analysis. BMJ Open 2017;7:e011146.

https://doi.org/10.1136/bmjopen-2016-011146.

[5] de Vugt ME, Verhey FRJ. The impact of early dementia diagnosis and intervention on informal caregivers. Prog Neurobiol 2013;110:54-62.

https://doi.org/10.1016/j.pneurobio.2013.04.005.

[6] Mittelman MS, Ferris SH, Shulman E, Steinberg G, Levin B. A family intervention to delay nursing home placement of patients with Alzheimer disease. A randomized controlled trial. JAMA 1996;276:1725-31.

[7] Morris JC, Storandt M, Miller JP, McKeel DW, Price JL, Rubin EH, et al. Mild Cognitive Impairment Represents Early-Stage Alzheimer Disease. Arch Neurol 2001;58:397-405. https://doi.org/10.1001/archneur.58.3.397.

[8] Mitchell AJ, Shiri-Feshki M. Rate of progression of mild cognitive impairment to dementia - meta-analysis of 41 robust inception cohort studies. Acta Psychiatr Scand 2009;119:252-65. https://doi.org/10.1111/j.1600-0447.2008.01326.x.

[9] Albert MS, DeKosky ST, Dickson D, Dubois B, Feldman HH, Fox NC, et al. The diagnosis of mild cognitive impairment due to Alzheimer's disease:

Recommendations from the National Institute on Aging-Alzheimer's Association workgroups on diagnostic guidelines for Alzheimer's disease. Alzheimers Dement J Alzheimers Assoc 2011;7:270-9. https://doi.org/10.1016/j.jalz.2011.03.008.

[10] A re-examination of Montreal Cognitive Assessment (MoCA) cutoff scores - Carson - 2018 - International Journal of Geriatric Psychiatry - Wiley Online Library n.d. https://onlinelibrary.wiley.com/doi/abs/10.1002/gps.4756 (accessed June 26, 2020).

[11] Dautzenberg G, Lijmer J, Beekman A. Diagnostic accuracy of the Montreal Cognitive Assessment (MoCA) for cognitive screening in old age psychiatry: Determining cutoff scores in clinical practice. Avoiding spectrum bias caused by healthy controls. Int J Geriatr Psychiatry 2020;35:261-9. https://doi.org/10.1002/gps.5227.

[12] Tsoi KKF, Chan JYC, Hirai HW, Wong SYS, Kwok TCY. Cognitive Tests to Detect Dementia: A Systematic Review and Meta-analysis. JAMA Intern Med 2015;175:1450-8. https://doi.org/10.1001/jamainternmed.2015.2152.

[13] Benson AD, Slavin MJ, Tran T-T, Petrella JR, Doraiswamy PM. Screening for Early Alzheimer's Disease: Is There Still a Role for the Mini-Mental State Examination? Prim Care Companion J Clin Psychiatry 2005;7:62-9. 
[14] Szcześniak D, Rymaszewska J. The usefulness of the SLUMS test for diagnosis of mild cognitive impairment and dementia. Psychiatr Pol 2015. https://doi.org/10.12740/PP/OnlineFirst/43141.

[15] Roebuck-Spencer TM, Glen T, Puente AE, Denney RL, Ruff RM, Hostetter G, et al. Cognitive Screening Tests Versus Comprehensive Neuropsychological Test Batteries: A National Academy of Neuropsychology Education Paper. Arch Clin Neuropsychol 2017;32:491-8. https://doi.org/10.1093/arclin/acx021.

[16] Jacova C, Kertesz A, Blair M, Fisk JD, Feldman HH. Neuropsychological testing and assessment for dementia. Alzheimers Dement 2007;3:299-317. https://doi.org/10.1016/j.jalz.2007.07.011.

[17] Wild K, Howieson D, Webbe F, Seelye A, Kaye J. Status of computerized cognitive testing in aging: A systematic review. Alzheimers Dement 2008;4:428-37. https://doi.org/10.1016/j.jalz.2008.07.003.

[18] de Oliveira MO, Brucki SMD. Computerized Neurocognitive Test (CNT) in mild cognitive impairment and Alzheimer's disease. Dement Neuropsychol 2014;8:112-6. https://doi.org/10.1590/S1980-57642014DN82000005.

[19] Lim YY, Jaeger J, Harrington K, Ashwood T, Ellis KA, Stöffler A, et al. Three-Month Stability of the CogState Brief Battery in Healthy Older Adults, Mild Cognitive Impairment, and Alzheimer's Disease: Results from the Australian Imaging, Biomarkers, and Lifestyle-Rate of Change Substudy (AIBL-ROCS). Arch Clin Neuropsychol 2013;28:320-30. https://doi.org/10.1093/arclin/act021.

[20] Hammers D, Spurgeon E, Ryan K, Persad C, Barbas N, Heidebrink J, et al. Validity of a Brief Computerized Cognitive Screening Test in Dementia. J Geriatr Psychiatry Neurol 2012;25:89-99. https://doi.org/10.1177/0891988712447894.

[21] Dwolatzky T, Whitehead V, Doniger GM, Simon ES, Schweiger A, Jaffe D, et al. Validity of a novel computerized cognitive battery for mild cognitive impairment. BMC Geriatr 2003;3:4. https://doi.org/10.1186/1471-2318-3-4.

[22] Zygouris S, Tsolaki M. Computerized Cognitive Testing for Older Adults: A Review. Am J Alzheimers Dis Other Demen 2014;30. https://doi.org/10.1177/1533317514522852.

[23] Cucinotta D, Vanelli M. WHO Declares COVID-19 a Pandemic. Acta Bio-Medica Atenei Parm 2020;91:157-60. https://doi.org/10.23750/abm.v91i1.9397.

[24] Yang S, Flores B, Magal R, Harris K, Gross J, Ewbank A, et al. Diagnostic accuracy of tablet-based software for the detection of concussion. PLOS ONE 2017;12:e0179352. https://doi.org/10.1371/journal.pone.0179352.

[25] Groppell S, Soto-Ruiz KM, Flores B, Dawkins W, Smith I, Eagleman DM, et al. A Rapid, Mobile Neurocognitive Screening Test to Aid in Identifying Cognitive Impairment and Dementia (BrainCheck): Cohort Study. JMIR Aging 2019;2:e12615. https://doi.org/10.2196/12615.

[26] Using ADRC and Related Resources - Alzheimer's Disease Research Center n.d. http://depts.washington.edu/mbwc/adrc/page/research-resources (accessed September 1, 2020).

[27] Luo J, Xiong C. DiagTest3Grp: An R Package for Analyzing Diagnostic Tests with Three Ordinal Groups. J Stat Softw 2012;51:1-24.

[28] De Roeck EE, De Deyn PP, Dierckx E, Engelborghs S. Brief cognitive screening instruments for early detection of Alzheimer's disease: a systematic review. 
Alzheimers Res Ther 2019;11:21. https://doi.org/10.1186/s13195-019-0474-3.

[29] Gauthier S, Reisberg B, Zaudig M, Petersen RC, Ritchie K, Broich K, et al. Mild cognitive impairment. The Lancet 2006;367:1262-70. https://doi.org/10.1016/S0140-6736(06)68542-5.

[30] Neuropsychological Testing - an overview | ScienceDirect Topics n.d. https://www.sciencedirect.com/topics/medicine-and-dentistry/neuropsychological-te sting (accessed October 21, 2020).

\section{Acknowledgements/Conflicts/Funding Sources}

The following authors declare the following competing interests: $\mathrm{BH}, \mathrm{KS}, \mathrm{RHG}, \mathrm{SY}, \mathrm{HP}$, BK report personal fees from BrainCheck, outside the submitted work; $\mathrm{BH}$, RHG reports receiving stock options from BrainCheck.

Acknowledgments: Funding was provided by BrainCheck, Inc. Registry was provided by the University of Washington Alzheimer's Disease and Research Center along the Memory and Brain Wellness Center

Data Availability - Data may be made available by contacting the corresponding author with a data use agreement.

\section{Keywords}

- Computerized Cognitive Test

- BrainCheck

- Mild Cognitive Impairment

- Dementia

- Cognitive Decline

- Discriminability

- Health Technology 